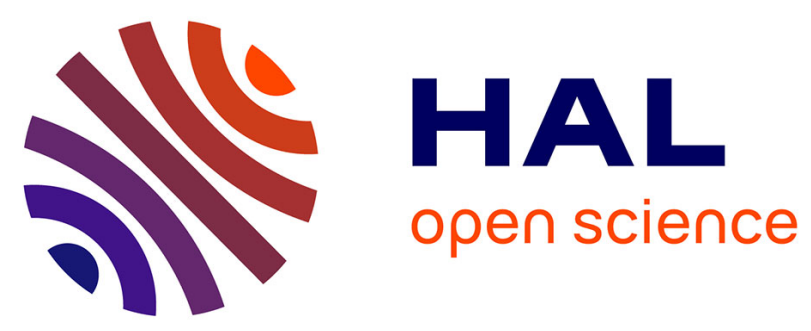

\title{
Multi-octave light source with tunable spectral profile: from supercontinuum to Raman comb spectral-structure
}

David Kergoustin, Foued Amrani, Benoît Debord, Frédéric Gérôme, Fetah Benabid

\section{- To cite this version:}

David Kergoustin, Foued Amrani, Benoît Debord, Frédéric Gérôme, Fetah Benabid. Multi-octave light source with tunable spectral profile: from supercontinuum to Raman comb spectral-structure. Conference on Laser and Electro-Optics /Europe (CLEO/Europe-EQEC 2019), Jun 2019, OSA, Jun 2019, Munich, Germany. Paper CD-9. hal-02330749

\section{HAL Id: hal-02330749 \\ https://hal.science/hal-02330749}

Submitted on 23 Nov 2020

HAL is a multi-disciplinary open access archive for the deposit and dissemination of scientific research documents, whether they are published or not. The documents may come from teaching and research institutions in France or abroad, or from public or private research centers.
L'archive ouverte pluridisciplinaire HAL, est destinée au dépôt et à la diffusion de documents scientifiques de niveau recherche, publiés ou non, émanant des établissements d'enseignement et de recherche français ou étrangers, des laboratoires publics ou privés. 


\title{
Multi-octave light source with tunable spectral profile: from supercontinuum to Raman comb spectral-structure
}

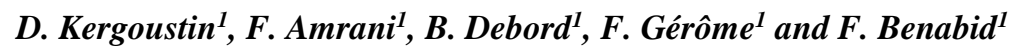 \\ 1. GPPMM group, Xlim research institute, CNRS UMR 7252, University of Limoges, France
}

Today it is possible to dispose from a large set of laser sources with broad spectra. Among these light sources, we list supercontinuum sources, generated by combination of several nonlinear phenomena [1], frequency combs generated either by using micro-resonators via optical Kerr effect [2] or Raman combs, generated via Stimulated Raman Scattering (SRS) in gas-filled Hollow-Core Photonic Crystal Fibers (HC-PCF) [3]. Some of these sources can generate spectra with a bandwidth that can span over several octaves, as demonstrated with the near-to 6 octaves Raman comb reported in [3].

Here we report on a single platform based on the combination of a Raman-gas filled Inhibited Coupling guiding HC-PCF (IC HC-PCF) and ultra-short pulse (USP) laser pump with tunable pulsewidth to generate, for the time to our knowledge, several octave wide light source which spectral structure can be tuned, just by changing the pump pulse duration, from a comb to a supercontinuum. This spectral transformation relies on the difference in the time response dependence between Kerr effect and SRS. For example in Raman gas such hydrogen, Kerr effect dominates for sub-picosecond pump pulses because of the instantaneous response of the material electronic hyperpolarizability in the Kerr phenomenon. In parallel, when a Raman gas is pumped with a pulse whose duration is larger than the generation-time of the Stokes, which is $\propto T_{2} / \sqrt{G}$ with $T_{2}$ being the molecular relaxation time and $G$ the Raman net gain, SRS dominates.

Fig. 1(a) shows the experimental setup. It is composed of a USP laser emitting up to $35 \mathrm{~W}$ average power at $1030 \mathrm{~nm}$ wavelength and $250 \mathrm{kHz}$ repetition rate, and with tunable pulse-duration spanning from 250 fs to $10 \mathrm{ps}$. The laser beam is sent before the fiber to a set of polarizing optics for power and polarization control. The input beam polarization is circular in order to enhance the excitation of the rotational resonances of hydrogen at 17.6 THz, as a linear polarization only excites vibrational resonances of $125 \mathrm{THz}$. The beam is then coupled into a 3 meters length Kagome IC HC-PCF with $57 \mu \mathrm{m}$ core diameter and a broadband low-loss guidance with a minimum of $10 \mathrm{~dB} / \mathrm{km}$ at the pumping wavelength. The fiber is filled with 20 bars of molecular hydrogen gas. The fiber output beam is analyzed by a spectrometer (Stellarnet) and optical spectrum analyzers (Ando and Yokogawa) for spectral characterization from $180 \mathrm{~nm}$ to $3400 \mathrm{~nm}$. Figs. 1(b-c) illustrate the output spectrum of the hydrogenfilled IC HC-PCF when excited with $15 \mathrm{~W}$ pump power for different pump pulse durations, from $250 \mathrm{fs}$ to $10 \mathrm{ps}$. Fig. 1(b) shows a photography of the diffracted beam profile spread across a screen, and Fig. 1(c) shows the recorded spectra. Both figures clearly show the spectral-transformation of the $\sim 3$ octaves wide spectrum - ranging from $\sim 370 \mathrm{~nm}$ in the UV to $\sim 2500 \mathrm{~nm}$ in the IR - from a ro-vibrational Raman frequency comb for pump pulsewidths wider than 2 ps and into a supercontinuum for pulsewidths between $250 \mathrm{fs}$ and 2 ps.

(a)

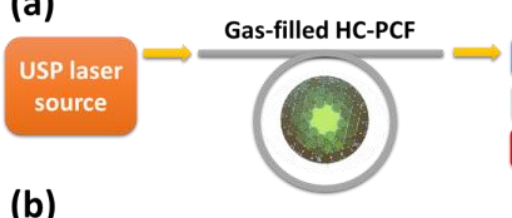

(b)

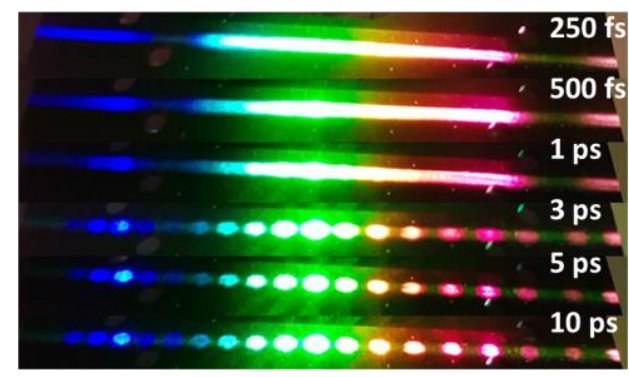

OSAs

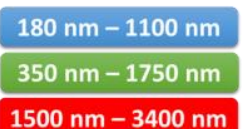
$1500 \mathrm{~nm}-3400 \mathrm{~nm}$

(c)

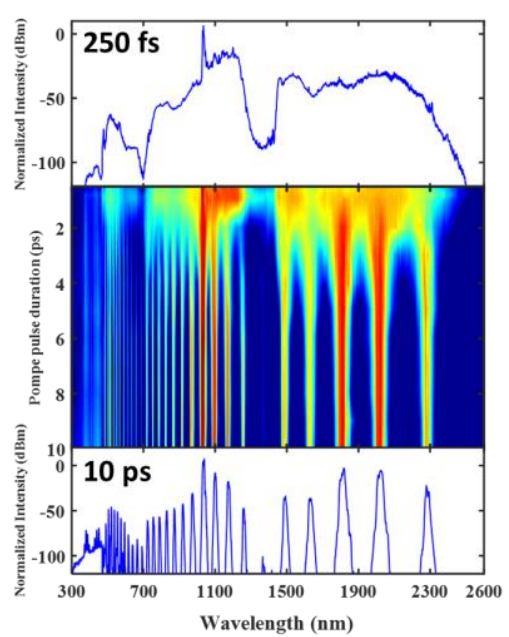

Fig. 1: (a) Experimental scheme, (b) Output beam scattered by an optical grating for different pump pulse durations, (c) Output spectrum, starting from supercontinuum (top) to Raman frequency comb (bottom) obtained using $8 \mathrm{~W}$ of average pumping power.

The authors acknowledge support from "Région Nouvelle-Aquitaine", $\Sigma \_$LIM Labex Chaire and DGA.

\section{References}

[1] Liao et al Appl. Phys. Express 6032503 (2013)

[2] Del'Haye et al. Nature 450, 1214-1217 (2007)

[3] Benoit et al. Optics Express 23(11) (2015) 